THE RESEARCH TRIANGLE 


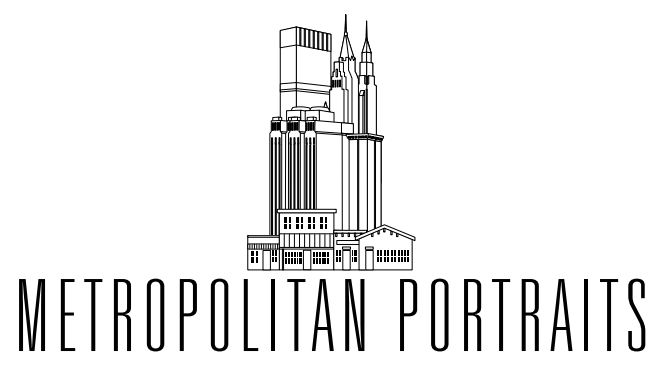

Metropolitan Portraits explores the contemporary metropolis in its diverse blend of past and present. Each volume describes a North American urban region in terms of historical experience, spatial configuration, culture, and contemporary issues. Books in the series are intended to promote discussion and understanding of metropolitan North America at the start of the twenty-first century. 


\section{THE RESEARCH TRIANGLE}

From Tobacco Road to Global Prominence

W I L L I A M M. ROHE

\section{$\overline{\text { PENN }}$}

University of Pennsylvania Press

Philadelphia 
Copyright (C) 2011 University of Pennsylvania Press

All rights reserved. Except for brief quotations used for purposes of review or scholarly citation, none of this book may be reproduced in any form by any means without written permission from the publisher.

Published by

University of Pennsylvania Press

Philadelphia, Pennsylvania 19104-4112

www.upenn.edu/pennpress

Printed in the United States of America on acid-free paper

10987654321

Library of Congress Cataloging-in-Publication Data

Rohe, William M.

The Research Triangle : from Tobacco Road to global prominence / William M. Rohe.-1st ed.

p. cm.- (Metropolitan portraits)

Includes bibliographical references and index.

ISBN 978-0-8122-4343-7 (hardcover : alk. paper)

1. Research Triangle Park Region (N.C.). 2. Research Triangle Park (N.C.)History. 3. Research Triangle Park Region (N.C.)-Economic conditions.

4. Research Triangle Park Region (N.C.)-Social conditions. 5. Regional planning-North Carolina-Research Triangle Park Region. I. Title. II. Series: Metropolitan portraits.

F262.R27R64 2011

$975.6^{\prime} 55-\mathrm{dc} 22$

2011011182 
For Jamie, Devon, and Kyla, who make my world go around 
